\title{
Inventory Model for Ramp type items with Trade Credit under Extra ordinary purchase
}

\author{
Suchismita Pradhan ${ }^{1}$, P.K. Tripathy ${ }^{2}$ \\ ${ }^{1}$ (Dept. of Mathematics, OrissaEngineering college,Bhubaneswar-751007, India) \\ ${ }^{2}$ (P.G. Department of Statistics, Utkal University,Bhubaneswar-751004, India)
}

\begin{abstract}
We have endeavoured here to depict an interactive inventory model between producer (supplier) and prospective buyer (vendor) in the presence of an extraordinary purchase and credit period with two parameter weibull deterioration for items with ramp type demand. The case of shortages is also studied.Additonally, we deal with the problem of a supplier disposing a large inventory level through an offer to a prospective buyer in the form of a credit period. From our model we confirm that the behaviour of replenishment period and trade credit period and change of the total variable cost observed from numerical evidence should be interpreted with caution in any business organisation.
\end{abstract}

Keywords: credit period, ramp type demand, shortages, Weibull deterioration

\section{Introduction}

The trade credit period offered by the supplier to the retailer, encourages retailer to buy more and it is a powerful promotional tool that attracts vendor to go for extra ordinary purchases. An inventory model is developed in which inventory are replenished in ramp type admitting a weibull deterioration and the supplier offers the progressive trade credit to the buyer. A progressive trade credit means that trade forwarding is carried out as follows: if the retailer pays the outstanding amount the permissible delay period the supplier does not charge any interest. If the payment is done after this period, the retailer will have to pay interest charges. Ramp type demand is one in which demand increase up to a certain time after which it stabilizes and become constant. Ramp type demand precisely depicts the demand of the items, such as newly launched fashion goods and cosmetics, garments, automobiles etc., for which the demand increases as they are launched into the market and some time after it becomes constant.

The model is quite easy as a negotiating tool especially, since no reaction is anticipated from other suppliers and/or other buyers to this type of offer. This is so because such practices are acceptable within the logistic industry because the once-and-for all nature of the offer itself precludes other firms from reacting on time. In fact, the ability to discriminate across prospective wholesalers with minimum disruption of accepted business practices, quite often vendors, the credit period is more attractive payment reduction mode when confronted with large levels of inventory of a particular commodity, a suppliers approach towards the availability of the extra stock for which demands from wholesaler behave ramp but deteriorate weibull, can be averred as an offer to the prospective buyer for an extra ordinary purchase under defined credit period within which no payment is required, in exchanges for the purchase of an additional units offer over and above the regular order.

The work of the researches who used ramptype demand as demand function for the formulation of economic order quantity inventory model is summarized in the following table :

\begin{tabular}{|c|c|c|c|c|}
\hline Reference & Objectives & Constraints & Contributions & Limitations \\
\hline $\begin{array}{l}\text { Mandal \& } \\
\text { Pal (13) } 1998\end{array}$ & $\begin{array}{l}\text { Finding } \\
\text { EOQ }\end{array}$ & $\begin{array}{l}\text { Ramp type demand, const, } \\
\text { rate of deteriorations. } \\
\text { Shortage not allowed }\end{array}$ & $\begin{array}{l}\text { An approximate Solution for EOQ } \\
\text { is obtained }\end{array}$ & $\begin{array}{l}\text { Approxi-mate Solution, } \\
\text { Const. rate of deteriora-tion }\end{array}$ \\
\hline $\begin{array}{l}\text { Kun-Shan \& } \\
\text { ouyang (12) } \\
2000\end{array}$ & $\begin{array}{l}\text { Finding } \\
\text { EOQ }\end{array}$ & $\begin{array}{l}\text { Ramp type demand, Const, } \\
\text { rate of deterioration shortage } \\
\text { allowed }\end{array}$ & $\begin{array}{l}\text { An exact solution for EOQ is } \\
\text { obtained }\end{array}$ & Constant rate of deteriora-tion \\
\hline $\begin{array}{l}\text { Kun-Shan } \\
{[1], 2001}\end{array}$ & $\begin{array}{l}\text { Finding } \\
\text { EOQ }\end{array}$ & $\begin{array}{l}\text { Ramp type demand weibull } \\
\text { deteriorations, shortage } \\
\text { allowed, Partial back } \\
\text { logging }\end{array}$ & $\begin{array}{l}\text { EOQ obtained for } 3 \text { numerical } \\
\text { examples }\end{array}$ & $\begin{array}{l}\text { Method explained by } \\
\text { numerical examples }\end{array}$ \\
\hline
\end{tabular}


A glance at the above table reveals that different researchers developed EOQ models by taking ramp type demand, deterioration (constant/weibull distribution) and shortage (allowed/not allowed/in starting). Out of these researchers only (12) and (2) obtained and exact solution for EOQ.

The motivation behind developing an EOQ model in the present paper is to introduce time dependent rate of deterioration(two parameter weibull distribution deterioration) incorporating ramp type demand with the conditions of permissible delay in payments. Main emphasis is laid on working out an exact solution for the desired model. An example is provided which stands in support of the developed model. In section 2, assumption and notations are presented. Section 3, the mathematical model is formulated and in section 4, numerical examples are cited to illustrate the model and sensitivity analysis of the optimal solution with respect to trade credit period is carried out.

\section{Assumptions And Notations}

\section{Assumptions}

The following assumptions are used to develop the mathematical model:

1. The inventory system deals with single item only.

2. Replenishment occurs instantaneously on ordering( i.e. lead time is zero).

3. No repair or replacement of deteriorated units.

4. Demand function $R(t)$ is taken to be ramp type function of time.

$$
R(t)=A e^{b[t-(t-\mu) H(t-\mu)]}
$$

where $H(1-\mu)$ is the well known Heaviside's step function defined as:

$$
H(t-\mu)= \begin{cases}1 & t \geq \mu \\ 0 & t<\mu\end{cases}
$$

And

$\mathrm{A}=$ initial demand rate

$\mathrm{b}=\mathrm{a}$ constant governing the exponential demand rate.

The pictorial representation of demand function $R(t)$ is shown in figure

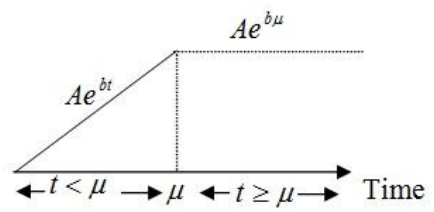

5. Shortages are allowed and backlogged.

\section{Notations:}

$I(t)$

$\phi(t)=\alpha \beta t^{\beta-1}$

$K, P, h, S$

$I_{e}, I_{r}$

$M$

$T, T_{1}$
$=$ Inventory level at time $t$.

$=$ Deterioration follows weibull distribution where $0<\alpha<1, \beta>0$.

$=$ Ordering cost of inventory $\$$ per order, purchase cost $\$$ per unit, holding cost excluding interest charges \$/unit / year, shortage cost \$/unit/year respectively.

$=$ interest earned, interest charges $\$ /$ year respectively where $I_{r} \geq I_{e}$.

= permissible delay in settling the accounts, $0<M<1$ year.

$=$ length of the replenishment cycle, time when shortages occur $\left(0 \leq T_{1}<T\right)$ respectively.

$T V C_{l}\left(T_{l}, T\right), T V C_{2}\left(T_{l}, T\right)=$ Average total inventory cost per unit time for $M \leq T_{l}$ and for $M>T_{l}$ respectively.

\section{Model Formulation}

The planning horizon is divided into sub-intervals of length $\mathrm{T}$ units. Orders are at time point $0, T, 2 T$,

$3 T$, ... being the order quantity being sufficient to bring the stock height to a certain maximum level.

Depletion of inventory occurs due to combined effects of demand and deterioration in the interval $0<t<T_{1}$. Demand is completely backlogged in the interval $T_{1}<t<T$. Variation of inventory level $I(t)$ with respect to time is given by

$$
\begin{aligned}
& \quad \frac{d I(t)}{d t}+\phi(t) I(t)=-R(t) \\
& \text { or } \quad \frac{d I(t)}{d t}+\alpha \beta t^{\beta-1} I(t)=-A e^{b[t-(t-\mu) H(t-\mu)]} \\
& 0<t<T_{l}
\end{aligned}
$$

For shortage the equation becomes 


$$
\begin{aligned}
& \frac{d I(t)}{d t}=-A e^{b[t-(t-\mu) H(t-\mu)]} \\
& T_{1}<t<T
\end{aligned}
$$

For $t \geq \mu$ the demand $R(t)$ becomes $A e^{b \mu}$ as $H(t-\mu)=1$.

Hence, equations (1) and (2) can be expressed as

$$
\frac{d I(t)}{d t}+\alpha \beta t^{\beta-1} I(t)=-A e^{b \mu}
$$

and $\frac{d I(t)}{d t}=-A e^{b \mu}$

with boundary condition $I\left(T_{1}\right)=0$

The solution of equation (3) is given by

$$
I(t)=\frac{A e^{b \mu}}{\alpha^{2} \beta^{2}}\left[\begin{array}{l}
T_{1}^{1-2 \beta}\left(\alpha \beta T_{1}^{\beta}+\beta-1\right) \\
e^{\alpha\left(T_{1}^{\beta}-t^{\beta}\right)}-t^{1-2 \beta}\left(\alpha \beta t^{\beta}+\beta-1\right)
\end{array}\right]
$$

for $0<t<T_{1}$ only for inventory and the solution of (4) is given by $I(t)=A e^{b \mu}\left(T_{1}-t\right)$ for $T_{1}<t<T$, only for shortage. Expected holding cost per unit per unit time is

$$
H C=h \int_{0}^{T_{1}} I(t) d t
$$

So,

$$
\begin{aligned}
\mathrm{HC} & =\frac{h A e^{b \mu}}{-\alpha^{2} \beta^{2}}\left[\frac{T_{1}^{1-2 \beta}\left(\alpha \beta T_{1}^{\beta}+\beta-1\right)\left\{\left(T_{1}^{1-\beta}-\left(\frac{1}{\beta}-1\right) T_{1}^{1-2 \beta} \cdot \alpha^{-1}\right\}\right.}{\alpha \beta}\right. \\
& \left.-\frac{\alpha \beta T_{1}^{2-\beta}}{2-\beta}-\frac{\beta T_{1}^{2-2 \beta}}{2-2 \beta}+\frac{T_{1}^{2-2 \beta}}{2-2 \beta}\right] \ldots \ldots \ldots \ldots \ldots \ldots . . .(7)
\end{aligned}
$$

Average number of deteriorated items $=I(0)-\int_{0}^{T_{1}} A e^{b \mu} d t$

$$
=\frac{A e^{b \mu}}{\alpha^{2} \beta^{2}}\left[T_{1}^{1-2 \beta}\left(\alpha \beta T_{1}^{\beta}+\beta-1\right) e^{\alpha T_{1}^{\beta}}\right]-A e^{b \mu} T_{1}
$$

Hence the expected deterioration cost per unit time is

$$
D C=P\left[\frac{A e^{b \mu}}{\alpha^{2} \beta^{2}}\left\{T_{1}^{1-2 \beta}\left(\alpha \beta T_{1}^{\beta}+\beta-1\right) e^{\alpha T_{1}^{\beta}}\right\}-A e^{b \mu} T_{1}\right] \ldots
$$

Over the interval $\left(T_{1}, T\right)$, expected shortage cost per unit per unit time

$$
S C=S \int_{T_{1}}^{T} A e^{b \mu}\left(T_{1}-t\right) d t
$$

So,

$$
S C=S A e^{b \mu}\left[T\left(T_{1}-\frac{T}{2}\right)-\frac{T_{1}^{2}}{2}\right]
$$

Panel-1: $M \leq T_{1}$

For $M \leq T_{1}$, the buyer has stock on hand beyond $M$ and so he can use the sale revenue to earn interest at an annual rate $I_{e}$ up to $T_{l}$. The interest earned, denoted by $I E_{l}$, is therefore,

$$
I E_{1}=P I_{e} \int_{0}^{T_{1}}\left(T_{1}-t\right) A e^{b \mu} d t=\frac{P I_{e} A e^{b \mu} T_{1}^{2}}{2}
$$

However, beyond the fixed credit period $\mathrm{M}$, the unsold stock is assumed to be financed with an annual rate $I_{r}$ and the interest payable, denoted by IP, is given by 


$$
I P=P I_{r} \int_{M}^{T_{1}} A e^{b \mu} d t=P I_{r} A e^{b \mu}\left(T_{1}-M\right)
$$

Therefore, the total average cost in this case comes out to be

$$
\begin{aligned}
& T V C_{1}\left(T_{1}, T\right)=\frac{K+H C+D C+S C+I P-I E_{1}}{T} \\
& =\frac{K}{T}-\frac{h A e^{b \mu}}{\alpha^{2} \beta^{2} T}\left[\frac{T_{1}^{1-2 \beta}\left(\alpha \beta T_{1}^{\beta}+\beta-1\right)\left(T_{1}^{1-\beta}-\left(\frac{1}{\beta}-1\right) T_{1}^{1-2 \beta} \cdot \alpha^{-1}\right.}{\alpha \beta}\right) \\
& \left.-\frac{\alpha \beta T_{1}^{2-\beta}}{2-\beta}-\frac{\beta T_{1}^{2-2 \beta}}{2-2 \beta}+\frac{T_{1}^{2-2 \beta}}{2-2 \beta}\right] \\
& +\frac{P}{T}\left[\frac{A e^{b \mu}}{\alpha^{2} \beta^{2}}\left\{T_{1}^{1-2 \beta}\left(\alpha \beta T_{1}^{\beta}+\beta-1\right) e^{\alpha T_{1}^{\beta}}\right\}-A e^{b \mu} T_{1}\right] \\
& +S A e^{b \mu}\left[T\left(T_{1}-\frac{T}{2}\right)-\frac{T_{1}^{2}}{2}\right]+\frac{P I_{r} A e^{b \mu}}{T}\left(T_{1}-M\right)-\frac{P I_{e} A e^{b \mu} T_{1}^{2}}{2 T}
\end{aligned}
$$

The optimal values of $T_{1}$ and $T$ (say $T_{1}^{*}$ and $T^{*}$ ) which minimize total average cost per unit per unit time, can be obtained by solving the following equations simultaneously

$$
\frac{\partial T V C_{1}\left(T_{1}, T\right)}{\partial T_{1}}=0 \text { and } \frac{\partial T V C_{1}\left(T_{1}, T\right)}{\partial T}=0
$$

Provided they satisfy the sufficient conditions

$$
\frac{\partial^{2} T V C_{1}\left(T_{1}, T\right)}{\partial T_{1}^{2}}>0, \frac{\partial^{2} T V C_{1}\left(T_{1}, T\right)}{\partial T^{2}}>0
$$

and

$$
\left[\left\{\frac{\partial^{2} T V C_{1}\left(T_{1}, T\right)}{\partial T_{1}^{2}}\right\}\left\{\frac{\partial^{2} T V C_{1}\left(T_{1}, T\right)}{\partial T^{2}}\right\}-\left\{\frac{\partial^{2} T V C_{1}\left(T_{1}, T\right)}{\partial T_{1} \partial T}\right\}^{2}\right]>0
$$

Panel-2: $M>T_{1}$

Since $M>T_{1}$, the retailer pays no interest but earns interest at an annual rate $I_{e}$ during the period $(0, \mathrm{M})$. But during $[0, \mathrm{~T}]$, the retailer sells product at selling price P/unit and deposits the revenue into interest earning account at the rate of $I_{e} / \$ /$ year. In the period $[T, M]$, the retailer deposits only the total revenue into an account that earns $I_{e} / \$ /$ year. Hence, interest earned per time unit is

$$
\begin{aligned}
I E_{2} & =P I_{e}\left[\int_{0}^{T_{1}}\left(T_{1}-t\right) A e^{b \mu} d t+\int_{0}^{T_{1}}\left(M-T_{1}\right) A e^{b \mu} d t\right] \\
& =P I_{e} A e^{b \mu}\left[M T_{1}-\frac{T_{1}^{2}}{2}\right]
\end{aligned}
$$

Then the total average cost per unit time is

$$
\begin{gathered}
T V C_{2}\left(T_{1}, T\right)=\frac{k+H C+D C+S C-I E_{2}}{T} \\
=\frac{K}{T}-\frac{h A e^{b \mu}}{\alpha^{2} \beta^{2} T}\left[\begin{array}{l}
\frac{T_{1}^{1-2 \beta}\left(\alpha \beta T_{1}^{\beta}+\beta-1\right)\left(T_{1}^{1-\beta}-\left(\frac{1}{\beta}-1\right) T_{1}^{1-2 \beta} \cdot \alpha^{-1}\right)}{\alpha \beta} \\
-\frac{\alpha \beta T_{1}^{2-\beta}}{2-\beta}-\frac{\beta T_{1}^{2-2 \beta}}{2-2 \beta}+\frac{T_{1}^{2-2 \beta}}{2-2 \beta}
\end{array}\right] \\
+\frac{P}{T}\left[\frac{A e^{b \mu}}{\alpha^{2} \beta^{2}}\left\{T_{1}^{1-2 \beta}\left(\alpha \beta T_{1}^{\beta}+\beta-1\right) e^{\alpha T_{1}^{\beta}}\right\}-A e^{b \mu} T_{1}\right]
\end{gathered}
$$


Inventory Model for Ramp type items with Trade Credit under Extra ordinary purchase

$$
+\frac{S A e^{b \mu}}{T}\left[T\left(T_{1}-\frac{T}{2}\right)-\frac{T_{1}^{2}}{2}\right]+\frac{P I_{e} A e^{b \mu}}{T}\left[M T_{1}-\frac{T_{1}^{2}}{2}\right]
$$

The optimal values of $\mathrm{T}_{1}$ and $\mathrm{T}$ (say $T_{1}^{*}$ and $T^{*}$ ), which minimize total average cost per unit per unit time, can be obtained by solving the following equations simultaneously.

$$
\frac{\partial T V C_{2}\left(T_{1}, T\right)}{\partial T_{1}}=0 \quad \text { and } \quad \frac{\partial T V C_{2}\left(T_{1}, T\right)}{\partial T}=0
$$

Provided these satisfy the sufficient conditions

$$
\frac{\partial^{2} T V C_{2}\left(T_{1}, T\right)}{\partial T_{1}^{2}}>0 \text { and } \frac{\partial^{2} T V C_{2}\left(T_{1}, T\right)}{\partial T^{2}}>0
$$

and

$$
\left[\left\{\frac{\partial^{2} T V C_{2}\left(T_{1}, T\right)}{\partial T_{1}^{2}}\right\}\left\{\frac{\partial^{2} T V C_{2}\left(T_{1}, T\right)}{\partial T^{2}}\right\}-\left\{\frac{\partial^{2} T V C_{2}\left(T_{1}, T\right)}{\partial T_{1} \partial T}\right\}^{2}\right]>0
$$

Compute the optimal values of $\mathrm{T}_{1}$ and $\mathrm{T}$ (say $T_{1}^{*}$ and $T^{*}$ ) for a given value of $M$ such that these values must satisfy both the conditions of equations (12) and (14) respectively.

\section{Numerical Example}

To illustrate the preceding theory, the following example is considered. LetK=100, $\mathrm{h}=12, A=100, \mathrm{P}=200$, $S=30, \mathrm{~b}=0.08, \mu=0.12, \alpha=0.002, \beta=1.5, I_{r}=0.15, I_{e}=0.13$.

\section{TABLE -1}

Panel-1 $M \leq T_{1}$

\begin{tabular}{|l|c|c|c|}
\hline $\mathrm{M}$ & $\mathrm{T}_{1}$ & $\mathrm{~T}$ & $\mathrm{TVC}_{1}$ \\
\hline 5 & 95.76369 & 117.795334 & 101454.257812 \\
\hline 10 & 90.82537 & 107.173447 & 92978.382812 \\
\hline 15 & 88.88950 & 100.211868 & 85601.265625 \\
\hline 20 & 72.45267 & 74.584206 & $54197.382812^{* * *}$ \\
\hline 25 & 52.43768 & 53.186420 & 64794.816406 \\
\hline 30 & 48.23120 & 49.149250 & 74697.890625 \\
\hline 35 & 46.01540 & 46.054947 & 85235.234375 \\
\hline 40 & 43.97472 & 44.035244 & 96776.687500 \\
\hline 45 & 40.87325 & 36.323273 & 107567.923300 \\
\hline
\end{tabular}

TABLE -2

Panel-2 $M>T_{1}$

\begin{tabular}{|l|r|r|r|}
\hline $\mathrm{M}$ & $\mathrm{T}_{1}$ & $\mathrm{~T}$ & $\mathrm{TVC}_{1}$ \\
\hline 5 & 4.8528610 & 2239.550293 & 6814908.50000 \\
\hline 10 & 9.9910000 & 586.812317 & 1794847.50000 \\
\hline 15 & 13.5000000 & 348.279816 & 1062690.62500 \\
\hline 20 & 16.8457336 & 241.840912 & 730912.875000 \\
\hline 25 & 23.4326740 & 145.568481 & 420037.593700 \\
\hline 30 & 27.9364800 & 113.839600 & 309742.000000 \\
\hline 35 & 32.9955273 & 92.791710 & 228593.750000 \\
\hline 40 & 37.4598600 & 81.973366 & 178945.687500 \\
\hline 45 & 42.8763490 & 75.265831 & 136440.578120 \\
\hline 50 & 48.6598300 & 73.447083 & 106138.750000 \\
\hline 55 & 54.3686500 & 75.254250 & 87315.468750 \\
\hline 60 & 59.9962543 & 79.283096 & 76616.335938 \\
\hline 65 & 64.9540520 & 84.016418 & 71917.140625 \\
\hline 70 & 69.9952670 & 89.544540 & $70441.625000 * *$ \\
\hline 75 & 74.8652000 & 95.323685 & 71385.093750 \\
\hline 80 & 78.9943760 & 100.444275 & 73608.523438 \\
\hline
\end{tabular}


Inventory Model for Ramp type items with Trade Credit under Extra ordinary purchase

\begin{tabular}{|l|l|l|l|}
\hline 85 & 82.8765300 & 105.369896 & 76649.312500 \\
\hline 90 & 89.0194800 & 113.239166 & 82909.484375 \\
\hline
\end{tabular}

\section{Nature of Problem Studied:}

Numerical analysis suggests several conclusions. First an increase in ramp demand riskiness measured by variance of demand with market return leads to lower reorder point and lower lot size when the replenishment time is lower than the trade credit period. When replenishment time is greater, an increase in demand riskiness decreases the reorder point but may result in greater lot size. Second, the average inventory in each panel is a strictly decreasing function of the risk of demand. Then it is reasonable to infer that this value of the fixed opportunity cost of capital is a good approximation of the true risk of inventory investment in the given scenario. On the other hand, if the difference in replenishment and trade credit period is large, then it is not approximate to use this fixed cost of the capital in the cost minimization model for the given scenario.

Panel-1 and Panel-2 together indicate that the total cost is relatively insensitive to adjustment for small risk.

\section{Sensitivity Analysis of decision variables:}

\section{TABLE -3}

Case - I

\begin{tabular}{|c|c|c|c|c|}
\hline \multicolumn{2}{|c|}{ Parameters } & $\mathrm{T} 1$ & $\mathrm{~T}$ & TVC1 \\
\hline & $+50 \%$ & 72.426946 & 74.553215 & 54139.300781 \\
\hline & $+40 \%$ & 72.4364328 & 74.565796 & 54163.171875 \\
\hline & $+30 \%$ & 72.438624 & 74.567268 & 54165.71875 \\
\hline & $+20 \%$ & 72.439679 & 74.568581 & 54167.984375 \\
\hline & $+10 \%$ & 72.44845 & 74.579109 & 54187.89062 \\
\hline & $-10 \%$ & 72.45857 & 74.591309 & 54210.73437 \\
\hline & $-20 \%$ & 72.46232 & 74.59584 & 54219.136719 \\
\hline & $-30 \%$ & 72.46623 & 74.600571 & 54227.91015 \\
\hline & $-40 \%$ & 72.46659 & 74.601044 & 54228.57031 \\
\hline & $-50 \%$ & 72.469582 & 74.604668 & 54235.2343 \\
\hline \multirow{10}{*}{$\mathrm{h}$} & $+50 \%$ & 95.45692 & 95.470215 & 120169.7031 \\
\hline & $+40 \%$ & 93.7895 & 96.292313 & 106331.84375 \\
\hline & $+30 \%$ & 92.3689945 & 95.902901 & 99138.9375 \\
\hline & $+20 \%$ & 90.89457 & 95.409019 & 91993.24218 \\
\hline & $+10 \%$ & 88.7683 & 94.029984 & 84323.648488 \\
\hline & $-10 \%$ & 72.9857 & 77.399048 & 47065.51953 \\
\hline & $-20 \%$ & 88.76593 & 99.342888 & 62854.6284 \\
\hline & $-30 \%$ & 81.4678 & 90.829727 & 50835.296875 \\
\hline & $-40 \%$ & 77.89745 & 87.181267 & 42073.9570 \\
\hline & $-50 \%$ & 75.011295 & 84.348061 & 34159.80468 \\
\hline \multirow{10}{*}{$\mathrm{a}$} & $+50 \%$ & 88.8774 & 95.529678 & 118333.625 \\
\hline & $+40 \%$ & 81.76598 & 86.260284 & 99151.07031 \\
\hline & $+30 \%$ & 82.99876 & 87.856865 & 94187.8125 \\
\hline & $+20 \%$ & 86.978 & 93.044434 & 92435.29687 \\
\hline & $+10 \%$ & 88.789 & 95.413902 & 86687.78906 \\
\hline & $-10 \%$ & 120.96248 & 135.104996 & 80330.4375 \\
\hline & $-20 \%$ & 128.8794 & 143.230179 & 69007.5390 \\
\hline & $-30 \%$ & 120.6578 & 134.772934 & 62524.7929 \\
\hline & $-40 \%$ & 125.67835 & 140.068878 & 52675.5585 \\
\hline & $-50 \%$ & 127.9853 & 142.365585 & 43367.8828 \\
\hline \multirow{8}{*}{$\mathrm{P}$} & $+50 \%$ & 83.19765 & 94.409050 & 39183.277344 \\
\hline & $+40 \%$ & 84.0128645 & 94.35424 & 39240.0625 \\
\hline & $+30 \%$ & 84.678946 & 94.020721 & 39125.625 \\
\hline & $+20 \%$ & 86.1287 & 94.700768 & 39042.25 \\
\hline & $+10 \%$ & 86.9875 & 94.477814 & 39222.722656 \\
\hline & $-10 \%$ & 78.9545 & 81.497696 & 32758.792969 \\
\hline & $-20 \%$ & 91.99768 & 96.392921 & 39055.1875 \\
\hline & $-30 \%$ & 92.98564 & 95.948715 & 38431.378906 \\
\hline
\end{tabular}


Inventory Model for Ramp type items with Trade Credit under Extra ordinary purchase

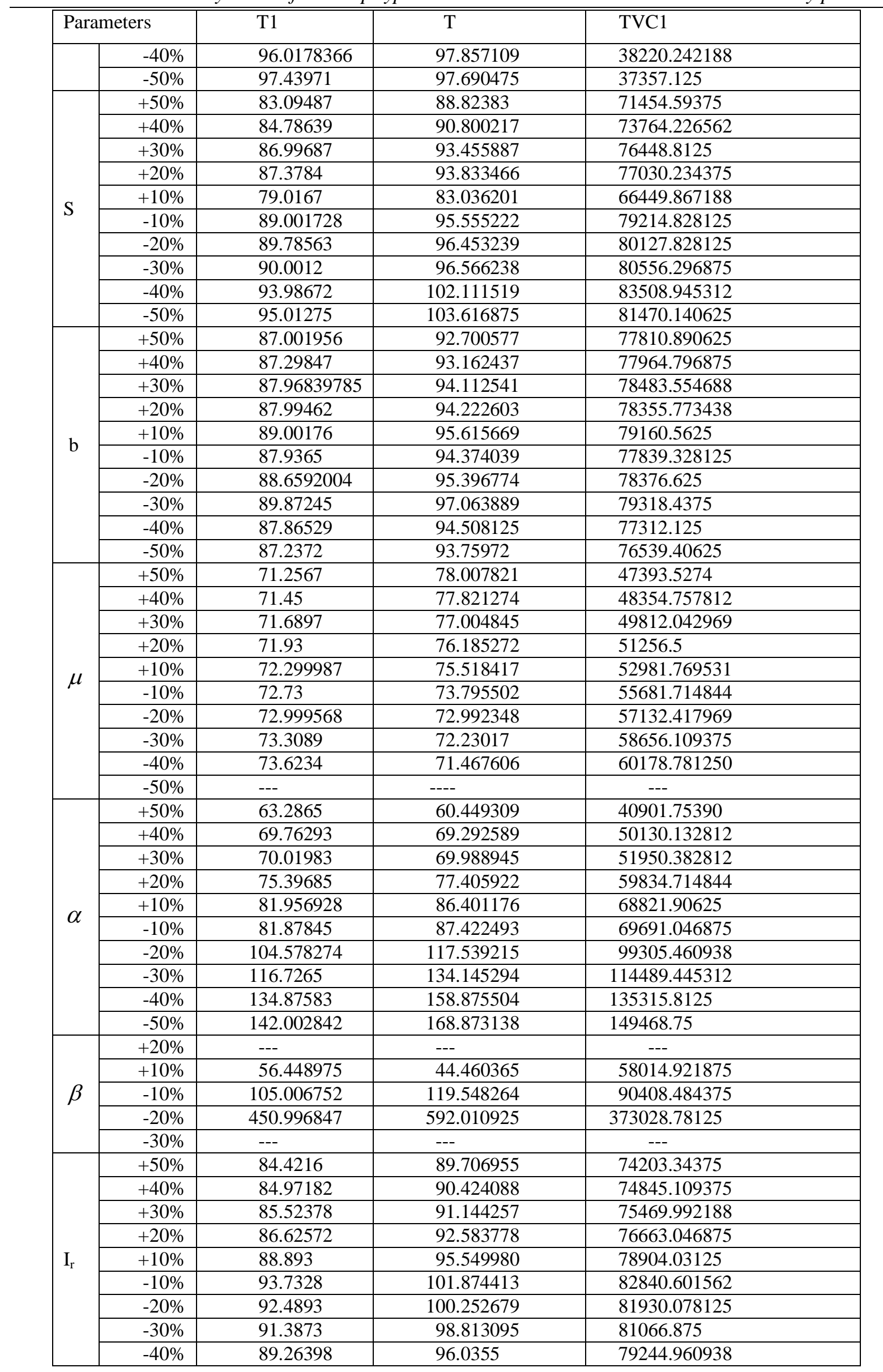


Inventory Model for Ramp type items with Trade Credit under Extra ordinary purchase

\begin{tabular}{|l|r|l|r|l|}
\hline \multicolumn{2}{|l|}{ Parameters } & T1 & T & TVC1 \\
\hline & $-50 \%$ & 87.4239 & 93.627579 & 77483.75 \\
\hline \multirow{6}{*}{$\mathrm{I}_{\mathrm{e}}$} & $+50 \%$ & 87.90182 & 105.105629 & 92516.1875 \\
\cline { 2 - 5 } & $+40 \%$ & 87.29856 & 102.141068 & 89306.42187 \\
\cline { 2 - 5 } & $+30 \%$ & 91.5328 & 106.093788 & 91035.015625 \\
\cline { 2 - 5 } & $+20 \%$ & 87.58753 & 98.300255 & 84091.023438 \\
\cline { 2 - 5 } & $+10 \%$ & 87.786592 & 96.365517 & 81200.625 \\
\cline { 2 - 5 } & $-10 \%$ & 78.653912 & 80.345985 & 62995.816406 \\
\cline { 2 - 5 } & $-20 \%$ & 73.984537 & 72.977371 & 51344.105469 \\
\cline { 2 - 5 } & $-30 \%$ & 81.98348 & 80.176331 & 60190.6875 \\
\cline { 2 - 5 } & $-40 \%$ & 87.97836 & 84.660141 & 61320.644531 \\
\hline
\end{tabular}

Table- 3 presents the results for the panel-1 when interest charge is large. A consistent observation is that both the total variable cost and the replenishment time period increases as the variance demand with inventory increases. Variance of demand with inventory increases, the lot size increases initially and then decreased. It seems that lot size is flexible so that it can be greater/lower depending on the cost structure of the firm and the variance of market demand with the on hand inventory level. The table demonstrates that the benefit of using risk adjusted inventory policies in total variable cost can be significant only when $\alpha$ increases less than $30 \%$. Our result shows, how an increase in total inventory cost may lead to an increased risk of $k, S, b$, $\mu$ and $I_{r}$. Firms with large time replenishment should have use a lower value of parameters $h, a, p$ and $I_{e}$ of capital input compensate for the increased risk of cash flows. This compliments the contentions of many practitioners about demand process, deterioration, sales and shortage and thereby the determination of the behaviour of the inventory process. This structure seems to be useful in providing insight into the problem as a whole and clarifying the different interactions within the spectrum of model variations.

This is not only accounts for the higher riskiness of cash flows, but also gives incentives to reduce the cost and control their inventory levels more meaningfully. Such an effort could also provide a number of other indirect benefits like improved quality, and less deterioration.

The sensitivity of the behaviour of decision variables trade credit and time replenishment is some what erratic in Panel-2 if the time for replenishment exceeds the trade credit period.

\section{Scope and Limitations}

An economic order quantity model has been developed considering ramp type demand, incorporating some realistic features such as deterioration, supplies credits and shortages. The credit approach permits a proper recognition of the financial implication of the opportunity cost in inventory analysis. Some items such as fashionable clothes, domestic goods (newly launched), luxury items, electronics products are easily identifiable with such kind of setup. The model is very practical since often the retailer has the capital with him, but business sense makes him to take advantage of the supplier credit.

The extent to which the credit period has affected the business world is clearly elucidated through the result, where the effect of credit period is visible shown over the total system cost.

\section{Concluding remarks}

Firms with a large replenishment time and high variance of demand with the market return can benefit subcutaneously by using risk adjustment policy as indicated by reduction of total variable cost. We reiterate that the behaviour should be interpreted with caution for both replenishment period and trade credit period and change in total variable cost observed from numerical evidence should be interpreted with caution. However, the penalties are relatively small when the opportunity cost of capital is small. This suggests that the penalty in present cost from using a large value of opportunity cost of capital can be as high as $20 \%$. The cost minimization model should be lower for firms with shorter replenishment times than for firms with large replenishment times. On the other hand when demand is high the penalty of using a low value of opportunity cost of capital can be as high as $10 \%$. This suggests that the opportunity cost of capital in the cost minimization model should be higher for firms with large replenishment time and large variance of demand.

Some extensions to this model appear feasible. One possibility is to consider the effect of indicating the special order when the on-hand inventory is not zero. The incorporation of default risk may provide additional insights. We restrict our consideration to single stage manufacturing items of ramp type demand. In addition, our results might also be useful for multistage items where different items are demanded variously. The developed model may be generalised by assuming a multiperiod version and its variations. However, these extensions perhaps require different mathematical methods. The study of these issues justifies additional 
research. Researchers on developing performance evaluation measures index could also profit form anchoring the concept of maximizing the value of the firm.

There is ample scope for further extension for research and study. For example, we may extend the model by introducing the inflation dependent demand to more generalized demand pattern that fluctuates with inflation and ramp type demand rate. Also, we could extend the model to incorporate some more features, such as quantity discount, two ware houses with multi-items in the system and permissible delay in payment with cash discount.

\section{References}

[1] WU Kun-Shan, An EOQ inventory model for items with weibull distribution deterioration, ramp type demand rate and partial backlogging, Production Planning and control, 12(2001), 787-793.

[2] Sanjay Jain and Kumar Mukesh ,An EOQ Inventory model with ramp type demand, weibull distribution deterioration and starting with shortage, OPSARCH Vol.44(2007), 240-250.

[3] T.Chakrabarty, B.C. Giri,. and K.S.Chaudhury, An EOQ Inventory Model for items with weibull distribution deterioration, shortages and trended demand: An extension of Philip's model, Computers and Operations Research, 25(1998), 649-657.

[4] A.K.Jalan, R.R.Giri,.a nd K.S.Chaudhuris, EOQ model for items with weibull distribution deterioration, shortages and trended demand, International Journal of system science, 27(1996), 851-856.

[5] N.H.Shah, and Y.K.Shah, A Discrete-In-Time Probabilistic Inventory Model for Deteriorating Items under conditions of Permissible delay in Payment, International Journal of System Science, 29(1998), 121-126.

[6] S.P.Aggarwal, and C.K.Jaggi, Ordering policies of Deteriorating items under conditions of permissible delay in payments. Journal of operational research society, 46(1995), 658-662.

[7] Manisha Pal, And K.Sanjay Ghosh, An Inventory model with stock dependent demand and general rate of deterioration under conditions of permissible delay in payments, vol.44( 2007), OPSEARCH, 227-239.

[8] S. Hardik., J.Shah, Bhavin and H.Shah Nita.: An EOQ model for deteriorating items with progressive payment sheme under DCF approach, Vol.43(2006), OPSEARCH, 238-257.

[9] A.M.M. Jamal, B.R Sarkar, S.Wang, Optimal payment time for a retailer under permitted delay payments by the wholesaler. International Journal of Production Economic 66(2000), 59-66.

[10] G.Padmanabhan, and P.Vrat, EOQ model for permissible items under stock dependent selling price, European Journal of operational Research, 8 .

[11] A. K Jalan, B. C. Giri, and K. S. Chaudhari, An EOQ model for items with weibull distributions deteriorations shortages and ramp type demand, Recent Development in operations Research, Narosa Publishing house,, New Delhi (India), (2001) 2007-223,

[12] WU Kun-Shan, and Liang -Yuh, Ouyand, A replenishment policy for deteriorating items with ramp type demand rate, , Proc. Natl. Sci. Counc. ROC (A), 24(2000) 279-286.

[13] B.Mandal, and A. K. Pal, Order level inventory system with ramp type demand rate for deteriorating items, Journal of Interdisciplinary Mathematics, 1 (1998), 49-66. 